\title{
The effectiveness of individual interpersonal psychotherapy as a treatment for major depressive disorder in adult outpatients: a systematic review
}

\author{
Madelon L J M van Hees ${ }^{1 *}$, Thomas Rotter ${ }^{1,2}$, Tim Ellermann ${ }^{3}$ and Silvia M A A Evers ${ }^{1,4}$
}

\begin{abstract}
Background: This systematic review describes a comparison between several standard treatments for major depressive disorder (MDD) in adult outpatients, with a focus on interpersonal psychotherapy (IPT).

Methods: Systematic searches of PubMed and PsycINFO studies between January 1970 and August 2012 were performed to identify (C-)RCTs, in which MDD was a primary diagnosis in adult outpatients receiving individual IPT as a monotherapy compared to other forms of psychotherapy and/or pharmacotherapy.

Results: 1233 patients were included in eight eligible studies, out of which 854 completed treatment in outpatient facilities. IPT combined with nefazodone improved depressive symptoms significantly better than sole nefazodone, while undefined pharmacotherapy combined with clinical management improved symptoms better than sole IPT. IPT or imipramine hydrochloride with clinical management showed a better outcome than placebo with clinical management. Depressive symptoms were reduced more in CBASP (cognitive behavioral analysis system of psychotherapy) patients in comparison with IPT patients, while IPT reduced symptoms better than usual care and wait list condition.

Conclusions: The differences between treatment effects are very small and often they are not significant. Psychotherapeutic treatments such as IPT and CBT, and/or pharmacotherapy are recommended as first-line treatments for depressed adult outpatients, without favoring one of them, although the individual preferences of patients should be taken into consideration in choosing a treatment.
\end{abstract}

Keywords: Interpersonal psychotherapy, Major depressive disorder, Systematic review

\section{Background}

Major depressive disorder (MDD) is a mental disorder characterized by a depressed mood, diminished interest or pleasure, sleeping problems and tiredness, and negative thoughts [1]. The mean one-year-prevalence of depression in European inhabitants between 18 and 65 years old is 6.9\% [2], and 16.2-16.6\% of US adults develop a major depressive disorder $[3,4]$. Furthermore, depression causes a high burden worldwide, taking fourth place in a ranking of

\footnotetext{
* Correspondence: mljm.vanhees@alumni.maastrichtuniversity.nl ${ }^{1}$ Caphri, School of Public Health and Primary Care; Faculty of Health, Medicine, and Life Sciences, Maastricht University, Maastricht, the Netherlands

Full list of author information is available at the end of the article
}

leading contributors to the burden of diseases in 2000. In 2020, it is estimated that depression will take second place in the ranking for all ages and sexes [5]. Moreover, depression is the leading cause of years of life lived with disability, in all ages and sexes, accounting for $11.9 \%$ of all disability [6]. Since it appears that persons suffering from mental disorders make more use of health care services [7], the increasing prevalence of depression leads to an increase in health care costs.

Research [8] and Dutch guidelines [9] suggest treating depression with psychotherapy and/or medication. Psychotherapy follows several kinds of methodologies. For depression, Cognitive (Behavior) Therapy (CBT) and Interpersonal Psychotherapy (IPT) are often applied. CBT 
originates from behavior therapy and cognitive therapy, and combines elements of both therapies [10-12]. IPT was originally developed for treating acute depression by improving the interpersonal functioning with important others [13-17]. This study will focus on the effectiveness and efficacy of IPT, since CBT has been subject of many studies up until now, while IPT has only recently become a subject of interest.

As a monotherapy for adults, individual IPT appears to be an effective treatment for depression [18-20], and several reviews [21-25], and meta-analyses [26-33] have been performed on the effectiveness of all kinds of methodologies of psychotherapy. Nevertheless, psychotherapy is a broad concept, and reviews and meta-analyses have often focused on different combinations of psychotherapy for treating depression without comparing one specific sole treatment to another [21,25-30,32,34]. Furthermore, although sole individual IPT appears to be effective, few reviews focus on sole individual IPT in adults with MDD as a primary diagnosis. Often, dissimilar study populations are compared with each other, for example adult, adolescent, and elderly patients in one study [23,25-30,33-35]. Furthermore, several more types of depression exist: dysthymic disorder or depression with medical conditions, for example, but this review will focus only on MDD. Chronic MDD and postpartum depression (PPD) will be included in this systematic review, for the following reasons. First of all, treatment for patients with chronic and non-chronic depression is equal in terms of content and structure. Therefore, the treatments of these patient groups are comparable. Secondly, the symptoms of both kinds of depression are comparable in terms of severity and content, which makes the patients comparable. Furthermore, women with PPD experience the same kind of symptoms as patients with MDD.

Since comorbidity is very common in patients suffering from depression, and this possibly increases the severity of the depression [36-44], this review will focus on MDD as a primary diagnosis with possible comorbidity.

Other factors influencing the results of previously executed systematic reviews include different age groups, in which form the provided IPT is administered, distinct settings, and the time periods during which the studies were executed. IPT is often adjusted for applicability to elderly [45] or adolescent [46] depressed patients, or in the form of group IPT [47]. Therefore, these kinds of treatments may be hard to compare with each other. That is why this review focuses on individual IPT. From here on, when IPT is described in the review, individual IPT is meant, unless described otherwise. Furthermore, the setting in which treatment takes place suggests the depression's level of severity. It is assumed that inpatients have a more severe depression, which is harder to treat. In addition, inpatient care is often multidisciplinary, which makes it difficult to examine the effects of separate therapies.
Research has been conducted on IPT since the 70s, which is why the date limit for this review is set on 1970. This review will give an overview of studies published between January 1970 and August 2012, with a focus on sole IPT administered to adults. Since some therapies have an effect relatively quickly, we did not apply a minimum for duration of a therapy.

With all of the above in mind, the aim of this study is to give an overview of recent literature describing the effectiveness and efficacy of sole individual IPT in comparison with standardized forms of treatment for treating patients with MDD as a primary diagnosis. The following research question has been formulated: Is individual interpersonal psychotherapy more preferable in comparison with other standardized forms of treatment for treating adult outpatients with a primary diagnosis of major depressive disorder?

In order to answer this question, a systematic review will be performed on RCTs and C-RCTs comparing the effectiveness (the outcome of a new treatment compared to other kinds of treatment(s), usually in a clinical setting) or efficacy (the outcome of treatments in homogeneous patient groups, usually in an experimental setting) [48] of individual sole IPT with other standardized forms of treatment, for treating adult outpatients with MDD as a primary diagnosis.

\section{Methods}

This paragraph will outline which steps were taken in order to perform this systematic review. An overview of the methods used for data collection, study selection, and data analysis will be provided.

\section{Data sources}

RCTs about IPT for depression were collected by searching PubMed and PsycINFO for studies published between January 1970 and August 2012. The following medical subject heading $(\mathrm{MeSH})$ categories and keywords were used: depression, postpartum depression, major depressive disorder, dysthymic disorder, interpersonal psychotherapy, treatment outcome, clinical trials. The exact search terms and $\mathrm{MeSH}$ headings can be found in the additional files (Additional file 1 - Search strategy). All titles and abstracts were screened, and only studies which met the review inclusion criteria (see next paragraph and Table 1) were selected for further review. Citation tracking and snowballing techniques added studies to the second screening phase, in which selected studies were screened for eligibility using a predefined checklist (see Data analysis) (Additional file 2 - Checklist).

\section{Study selection}

Only studies with sufficient methodological quality meeting the inclusion criteria were selected for this review. The 
Table 1 Summary of inclusion and exclusion criteria

\begin{tabular}{lll}
\hline $\begin{array}{l}\text { Study } \\
\text { characteristic }\end{array}$ & Inclusion criteria & Exclusion criteria \\
\hline \multirow{2}{*}{ Type of study } & Randomized controlled trial & \\
\cline { 2 - 3 } & \multicolumn{1}{l}{ En70 } & $<1970$ \\
\cline { 2 - 3 } & English language & Other languages \\
\hline Population & Adults (18-65) & Elderly people or adolescents \\
\cline { 2 - 3 } & Major depressive disorder as a primary diagnosis & Bipolar disorder \\
\hline Interventions & Individual sole IPT & Group IPT \\
\hline Comparators & Other evidence-based psychotherapies, combined treatment, & Alternative therapy, bibliotherapy, complementary therapy, \\
& or pharmacotherapy & counseling, psychoeducation, supportive therapy \\
\hline Setting & Outpatient ambulant care, primary care & Inpatient care \\
\hline Outcome & Western jurisdictions & Outside of Western jurisdictions \\
\hline IPT Interpersonal Psychotherapy. & Depressive symptoms &
\end{tabular}

criteria for selection will be described shortly. An overview of the inclusion and exclusion criteria is provided in Table 1.

Studies were included if they were randomized or cluster-randomized evaluations (RCTs or C-RCTs) published in English after January $1^{\text {st }}, 1970$, and took place in western jurisdictions, to ensure high internal validity. These studies had to focus on MDD (non-chronic or chronic) as a primary diagnosis in adults (18-65 years old). The diagnosis must have been reached using a formal classification system, such as the Diagnostic and Statistical Manual of Mental Disorders (DSM) [1], the International Classification of Diseases (ICD) [49], or the Research Diagnostic Criteria [50]. Bipolar disorders as primary diagnoses were excluded, as well as cases where the patients were elderly people or adolescents, or in cases in which physical conditions might contribute to the (severity of) depressive symptoms. The proposed intervention must have been individual sole IPT, in comparison with other psychotherapies, pharmacotherapy, or combined treatment. Group IPT and other kinds of treatments were excluded. Studies executed in ambulant care or primary care were included, whereas inpatient care patients were excluded.

By making the inclusion criteria very strict, a more homogeneous group, with a narrower scope, was created, which made it possible to focus on clinical applicability of the treatments for these kinds of patients.

\section{Data analysis}

Before the data were analyzed for this review, the methodological quality of the studies included after screening has been assessed, using a predefined checklist (Additional file 2 - Checklist). This checklist was composed of Delphi-list questions [51] and questions assessing the risk of bias in effect evaluation studies [52]. General questions were composed for collecting relevant information about the study, after which the resulting information was entered in a Microsoft Excel table for a clear overview. This overview was used to create a table of evidence of the extracted study data, and to summarize the most important findings. $\mathrm{MH}$ performed the analysis and consulted TR in case of doubt. In this case, the analyses were double checked and consensus was reached.

\section{Results}

The literature search resulted in 3981 studies, of which 3911 were excluded from further review for several reasons, documented below. Figure 1 shows the flow diagram of included and excluded studies. Studies were excluded when they did not meet the inclusion criteria, based on the title and abstract: i.e. they did not focus on MDD as a primary diagnosis, on individual sole IPT, or the target group was anything other than adults. Another 62 were excluded after reading the full text, leaving 8 articles eligible for this review.

These 62 full-text articles were excluded for the following reasons: being reviews or meta-analyses [21-23,25$30,32,34,53-60]$, being a protocol for a study [61], being a study based on earlier/other studies [43,45,62-76], there was no comparison in the study [77], MDD was not the primary diagnosis [78-82], the study had the wrong aim for this review [83-86], there was no research data [87-91], or one of the interventions was not IPT as described in the eligibility criteria [35,92-100]. See Additional file 3 List of excluded studies for a detailed description of the reasons for exclusion.

\section{Description of the studies}

The main characteristics of the RCT studies included are summarized in Table 2. One study was carried out in the Netherlands [101], one in New Zealand [102], one in 


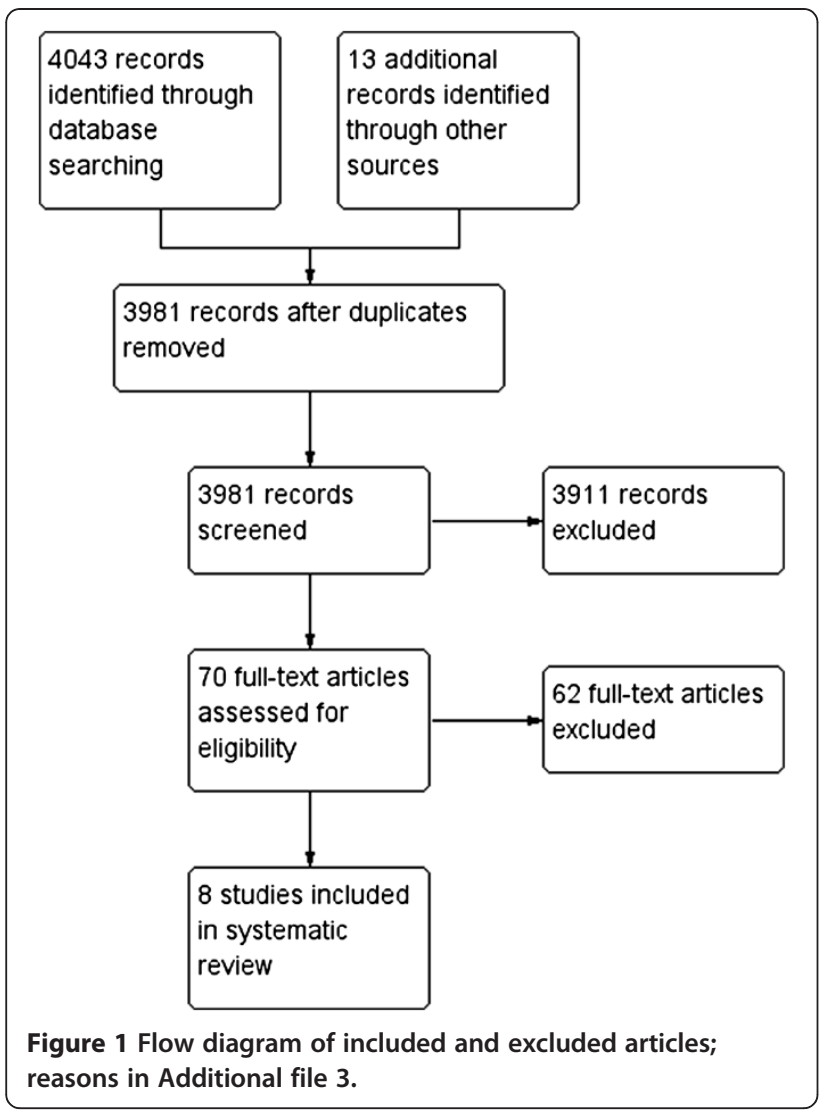

Canada [103], one in the UK [104], one in Germany [105], and three in the USA [106-108]. All studies clearly described eligibility criteria and success-of-treatment point. All but two [103,104] included an intention-to-treat analysis. Seven studies reported comparable sociodemographic and psychiatric variables at baseline. One [103] did not report these variables.

A total of 1233 patients were included in the review, of whom 854 completed treatment in outpatient facilities. Of the patients included, 392 received IPT, 14 received CBASP (Cognitive Behavioral Analysis System of Psychotherapy), 160 received CBT, 153 received pharmacotherapy (nefazodone, nortriptyline hydrochloride, or venlafaxine hydrochloride), 67 received pharmacotherapy plus clinical management, 49 received IPT and nefazodone, 47 received IPT and a placebo, 34 received a placebo plus clinical management, 92 received usual care consisting of communication with a physician for appropriate treatment, and 51 were put on a wait list. The mean age in seven studies [101,102,104-106] ranged from 29.4 to 40.2 years old, and the percentage of female patients varied from $55 \%$ to $83 \%$, except for one study, in which only females participated [108]. One study did not report these data [103]. All patients were diagnosed with non-psychotic MDD as a primary diagnosis according to the DSM-III-R [109], DSM-IV [110], or the Research Diagnostic Criteria [50].

IPT in all studies was based on a standardized manual $[14,17]$, as was CBASP [111] and CBT $[12,112,113]$. The number of IPT and CBT sessions varied from 8 to 24 in a 12- or 16-week period, and most of the sessions were held weekly. Physicians administering nefazodone or nortriptyline were instructed to follow a manual. Patients receiving nefazodone started at $100 \mathrm{mg}$ capsules per day, and doses were gradually increased to a minimum of $400 \mathrm{mg}$, with a maximum of $600 \mathrm{mg}$ [101]. Patients receiving nortriptyline started at $25 \mathrm{mg}$ per day, aiming for blood levels of 190-570 nmol/liter [106]. Patients receiving imipramine hydrochloride had a dosage between 150 and $185 \mathrm{mg}$. Pharmacotherapists administering venlafaxine followed an evidence-based protocol of $37.5 \mathrm{mg}$ twice-daily doses [104]. Pharmacotherapy plus clinical management was administered by a psychiatrist who followed the client for the duration of the protocol associated with the antidepressant medication [103], or as long as the clinical management would be administered [107].

\section{Risk of bias}

Risk of bias was measured and summarized (see Figure 2) according to the standards of the Cochrane Collaboration [52]. Although this was not always described exhaustively, all studies used randomization and seemed to present complete outcome data. Therefore, all included studies had a low risk of selection bias and attrition bias. Nevertheless, two studies $[103,107]$ had an unclear risk of detection bias and one of them [103] had a high risk of reporting bias. Another study [108] had a high risk of detection bias. Notwithstanding these higher levels of bias, these studies have been included in this review.

\section{Findings on outcome measurements}

The outcome of the HAMD showed an overall decrease in the level of depression over time $(p<0.001)$ between the four treatment conditions (IPT, nefazodone, IPT and nefazodone, IPT and placebo), but this was not statistically significant. A significant difference was found between IPT and nefazodone and the use of nefazodone without IPT in favor of the first (for the intent to treat sample: adjusted OR $(95 \% \mathrm{CI})=3.22(1.02-10.12), p=0.045)$. Furthermore, a significant difference was found in the MADRS scores. Patients receiving IPT with nefazodone improved more than did patients receiving nefazodone without IPT. Furthermore, the nefazodone condition showed only a small improvement after the first six weeks [101].

Imipramine hydrochloride combined with clinical management $(\mathrm{CM})$ was significantly superior to placebo with $\mathrm{CM}$ on general level of functioning. Patients receiving IPT or imipramine hydrochloride with $\mathrm{CM}$ appeared to 
Table 2 Summary of the characteristics of the includes studies

\begin{tabular}{|c|c|c|c|c|c|c|c|}
\hline Study & $\mathrm{N}$ included & $\begin{array}{l}\mathrm{N} \text { completed } \\
\text { treatment }\end{array}$ & $\begin{array}{l}\text { Population and } \\
\text { primary } \\
\text { diagnosis }\end{array}$ & Treatment types & $\begin{array}{l}\text { Duration } \\
\text { (weeks) }\end{array}$ & $\begin{array}{l}\text { Primary and } \\
\text { secondary outcome } \\
\text { measure }\end{array}$ & $\begin{array}{l}\text { Time between } \\
\text { pre- and post- } \\
\text { treatment }\end{array}$ \\
\hline \multirow{2}{*}{$\begin{array}{l}\text { Blom et al. } \\
\text { (2007) }\end{array}$} & \multirow[t]{2}{*}{193} & \multirow[t]{2}{*}{132} & \multirow[t]{2}{*}{ Adults with MDD } & \multirow{2}{*}{$\begin{array}{l}\text { IPT vs.Nefazodone vs.IPT } \\
\text { + nefazodone vs.IPT } \\
\text { + placebo }\end{array}$} & \multirow[t]{2}{*}{16} & HAMD & \multirow[t]{2}{*}{12 weeks } \\
\hline & & & & & & MADRS & \\
\hline \multirow{2}{*}{$\begin{array}{l}\text { Elkin et al. } \\
\text { (1989) }\end{array}$} & \multirow[t]{2}{*}{250} & \multirow[t]{2}{*}{155} & \multirow[t]{2}{*}{ Adults with MDD } & \multirow{2}{*}{$\begin{array}{l}\text { IPT vs. CBT vs. IMI-CM vs. } \\
\text { PLA-CM }\end{array}$} & \multirow[t]{2}{*}{16} & HRSD & \multirow[t]{2}{*}{16 weeks } \\
\hline & & & & & & $\mathrm{BDI}$ & \\
\hline \multirow{3}{*}{$\begin{array}{l}\text { Luty et al. } \\
\text { (2009) }\end{array}$} & \multirow[t]{3}{*}{177} & \multirow[t]{3}{*}{159} & \multirow[t]{3}{*}{ Adults with MDD } & \multirow[t]{3}{*}{ IPT vs.CBT } & \multirow[t]{3}{*}{16} & MADRS & \multirow[t]{3}{*}{16 weeks } \\
\hline & & & & & & HRSD & \\
\hline & & & & & & $\mathrm{BDI}$ & \\
\hline $\begin{array}{l}\text { Marshall } \\
\text { et al. } \\
\text { (2008) }\end{array}$ & 159 & 102 & Adults with MDD & IPT vs.CBT vs.PHT-CM & 16 & HRSD & 16 weeks \\
\hline \multirow{2}{*}{$\begin{array}{l}\text { Martin } \\
\text { et al. } \\
\text { (2001) }\end{array}$} & \multirow[t]{2}{*}{28} & \multirow[t]{2}{*}{28} & \multirow[t]{2}{*}{ Adults with MDD } & \multirow[t]{2}{*}{ IPT vs.Venlafaxine } & \multirow[t]{2}{*}{16} & HAMD & \multirow[t]{2}{*}{6 weeks } \\
\hline & & & & & & $\mathrm{BDI}$ & \\
\hline \multirow{2}{*}{$\begin{array}{l}\text { O'Hara } \\
\text { et al. } \\
\text { (2000) }\end{array}$} & \multirow[t]{2}{*}{120} & \multirow[t]{2}{*}{99} & \multirow[t]{2}{*}{ Women with PPD } & \multirow[t]{2}{*}{ IPT vs. WLC } & \multirow[t]{2}{*}{12} & HRSD & \multirow[t]{2}{*}{12 weeks } \\
\hline & & & & & & $\mathrm{BDI}$ & \\
\hline \multirow{2}{*}{$\begin{array}{l}\text { Schramm } \\
\text { et al. } \\
\text { (2011) }\end{array}$} & \multirow[t]{2}{*}{30} & 29 & Adults with early & IPT vs.CBASP & 16 with & HRSD & 16 weeks \\
\hline & & & $\begin{array}{l}\text { onset chronic } \\
\text { MDD }\end{array}$ & & $\begin{array}{l}12 \text { months } \\
\text { follow-up }\end{array}$ & $\overline{\mathrm{BDI}}$ & \\
\hline $\begin{array}{l}\text { Schulberg } \\
\text { et al. } \\
\text { (1996) }\end{array}$ & 276 & 150 & Adults with MDD & $\begin{array}{l}\text { IPT vs.Nortriptyline vs. } \\
\text { Usual care }\end{array}$ & $\begin{array}{l}16 \text { with } \\
8 \text { months } \\
\text { follow-up }\end{array}$ & HRSD & 8 months \\
\hline
\end{tabular}

CBASP Cognitive Behavioral Analysis System of Psychotherapy; CBT Cognitive Behavior Therapy; HAMD Hamilton Depression Rating Scale; HRSD Hamilton Rating Scale Depression; IMI-CM imipramine plus clinical management; IPT Interpersonal Psychotherapy; MADRS Montgomery-Åsberg Depression Rating Scale; MDD Major Depressive Disorder; PHT-CM pharmacotherapy plus clinical management; PLA-CM placebo plus clinical management; WLC wait list condition.

have a better outcome on the HRSD than patients receiving placebo with CM ( $p=0.018$ and $p=0.017)$. Furthermore, these patients showed a significantly higher percentage in the recovery analysis compared to placebo with $\mathrm{CM}$ patients, measured by a score of six or lower on the HRSD ( $p=0.010$ and $p=0.013$ ) [107].

In the Luty et al. study [102], depressive symptoms improved for about $55 \%$. No statistically significant differences were found between IPT and CBT on the primary outcome measure MADRS $(9.5 \%$ mean difference $(95 \%$ CI), $p=0.059)$, nor after controlling for baseline severity $(p=0.055)$.
HRSD scores were significantly higher in the IPT condition compared to the PHT-CM condition $(t(96)=-2.46$, $p<0.05, d=-0.50)$. No significant differences were found between IPT and CBT conditions $(t(96)=-1.19, p=0.46$, $d=-0.24)$, or between CBT and PHT-CM conditions $(t(96)=-1.35, p=0.37, d=-0.28)$ [103].

Depressive symptoms, measured by the HAMD and BDI, improved significantly $(p<0.001)$ in the first six weeks for patients receiving IPT or venlafaxine [104]. Although the venlafaxine group showed a slightly better outcome than the IPT group, no significant differences were found after six weeks.

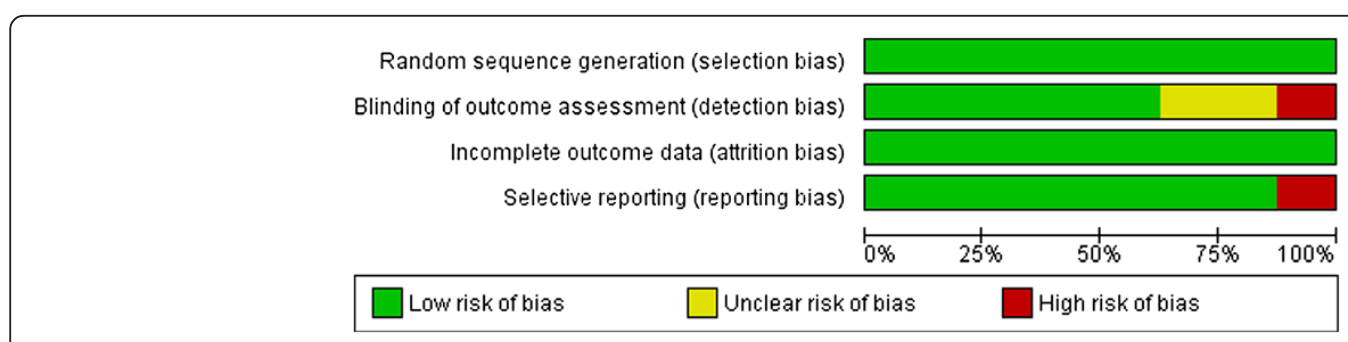

Figure 2 Summary of risk of bias in six studies. 
O'Hara described recovery rates for women with PPD based on HRSD scores and BDI scores, favoring IPT over wait list condition (WLC). Based on HRSD scores (HRSD $\leq 6)$, IPT had a recovery rate of $31.7 \%$, compared to $15 \%$ of WLC $(p=0.03)$. Based on BDI scores (BDI $\leq 9)$, IPT had a recovery rate of $38.3 \%$, while women in the WLC group showed a recovery rate of $18.3 \%(p=0.02)$ [108].

In both the IPT and CBASP group [105], HRSD scores decreased after 16 weeks, but only in the CBASP group statistical significance was reached $(t(13)=3.53$, $p=0.004)$. BDI scores were significantly lower after 16 weeks in both groups (IPT: $t(14)=2.34, p=0.034$; CBASP: $t(13)=5.01, p<0.001)$. HRSD scores did not show a significant difference between the groups, whereas BDI scores showed a significantly higher reduction in depressive symptoms in the CBASP group after 16 weeks (mean BDI score of 10.79 vs. 21.27 in IPT; $F(1,26)=4.34, p=0.047$, treatment effect size: Cohen's $d=0.87$ ).

Eight months after the start of the treatments (IPT, nortriptyline, or usual care), all HRSD scores improved significantly $\left(\chi^{2}=816.14, d f=6, p<0.001\right)$, and a significant difference was found between the groups $\left(\chi^{2}=14.92\right.$, $d f=2, \quad p=0.001)$. Post-hoc group $t$-test comparisons showed significant differences $(p<0.01)$ in HRSD scores between nortriptyline and usual care, at most measurement times favoring nortriptyline, and between IPT and usual care, favoring IPT after eight months. No significant difference was found between IPT and nortriptyline at any moment in time [106].

\section{Meta-analysis and summary of findings}

As can be seen in Table 2, heterogeneity between the studies exists, which made it difficult to make metaanalytic comparisons. However, three studies were comparable in terms of measuring the effects of IPT and CBT [102,103,107]. The mean difference between the treatments was 1.01 (95\% CI: $-0.34,2.37)$ favoring CBT over IPT, but did not reach a statistically significant level. See Figure 3 for more detailed information.

Although no further meta-analyses were possible, and results appeared to be inconsistent, some conclusions can be drawn from these studies. IPT combined with nefazodone improved MADRS scores significantly better than did nefazodone alone [101]. Furthermore, higher HRSD scores were found in IPT patients in comparison with PHT-CM patients [103]. IPT patients showed a significantly greater decrease of HRSD and BDI scores than WLC patients [108]. As measured with the BDI, depressive symptoms were reduced more in CBASP patients in comparison with IPT patients [105]. Finally, IPT patients produced lower HRSD scores in comparison with patients receiving usual care [106].

\section{Discussion}

\section{Main results}

The results of this systematic review show inconsistent findings in the eight heterogeneous studies included. The effectiveness and efficacy of the several treatments is comparable in most studies, and some conclusions may be drawn. Overall, the efficacy of IPT and CBT appears to be equal [102]. Contradictory results were found in IPT in comparison with pharmacotherapy. IPT combined with nefazodone appears to have a higher efficacy than sole nefazodone [101], while pharmacotherapy combined with clinical management appears to have a higher efficacy than IPT alone [103]. However, another study showed comparable results between IPT and imipramine hydrochloride with clinical management (CM), which both returned a better outcome on the HRSD compared to placebo with CM [107]. Furthermore, venlafaxine seems to reduce depressive symptoms more than IPT after six weeks, although this outcome was not significant [104]. The effects of using sole IPT and sole nortriptyline do not significantly differ from each other [106]. IPT and CBASP appear to be very comparable in efficacy, although scores of the BDI showed a slight preference for CBASP [105]. Finally, IPT appears to be more effective than wait list condition [108], and usual care after eight months, as does nortriptyline [106].

These outcomes suggest that several kinds of treatments are effective or efficacious for depressed patients, although one has to keep in mind the small number of

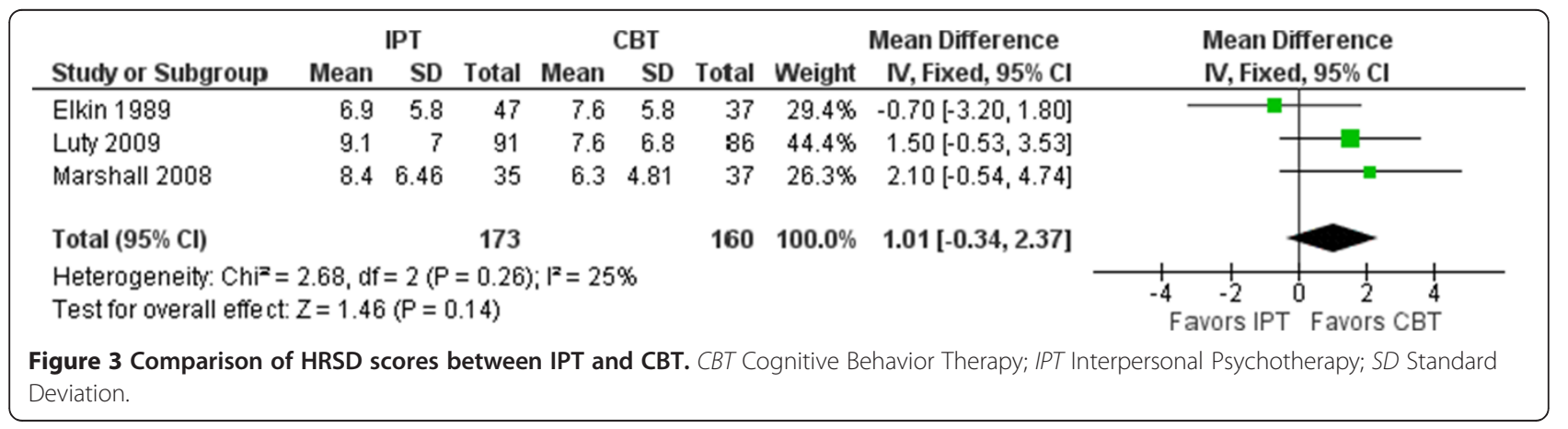


included studies. Patients are recommended to choose a treatment which fits their personal preferences, since this may affect the outcome of the treatment. Policy makers are advised to base regulations on the effectiveness and efficacy of treatments in general, instead of a slightly different effect between one treatment and the other, since these studies do not take individual differences and preferences into account.

\section{Limitations}

This review has a number of limitations. First, this review included only adult outpatients with unipolar, non-psychotic major depression as a primary diagnosis. Although these inclusion criteria were a deliberate choice, this review has consequences for the generalizability. These results are not generalizable to children, adolescents, or the elderly, to patients with other kinds of depression, or to patients suffering from a combination of depression and medical conditions, or from depression and substance abuse. Furthermore, no distinction has been made in the severity of depression, which causes a higher heterogeneity in the complete sample, making results more uncertain.

Second, only eight studies with a limited number of participants were included in this review. Although most studies showed a low risk of bias, the small size of the sample may increase this risk. Furthermore, results are harder to generalize with a small number of participants, especially because many different kinds of treatments have been compared with each other (high heterogeneity), which limited the number of participants in the groups not receiving IPT. Moreover, the limited number of included studies in this review, makes one question the applicability of the Cochrane guidelines for conducting a systematic review [52], for clinical treatments in mental health care.

Third, all included patients were outpatients and therefore had to be willing and motivated to participate in the selected studies. This may cause some bias, since not all types of patients could be included in the studies. For example, treatment-resistant depressed patients may have been less motivated than patients who were not treatmentresistant, and it may not be possible to generalize results for these patients.

Fourth, pharmacotherapy consisted of different types of antidepressant medication. Although these medications may seem to be equally effective, some differences may exist, which may interfere with the results of this review. Furthermore, one study [101] used nefazodone as pharmacotherapy, although this medication has been withdrawn in, amongst other countries, the USA and the Netherlands, because of hepatotoxicity associated with this drug [114].

Fifth, some of the findings were based on the scores of the HRSD [101,103-108]. However, this scale has recently been criticized for having multiple problems, including among others the existence of different versions and not being as sensitive as other scales [115,116]. Despite these flaws, the HRSD has been used in many studies and the outcomes of this scale can therefore not be excluded from this review. Furthermore, findings were also based on the MADRS [101,102], which is more sensitive to treatment effect than the HAMD [117], and on the BDI $[104,105]$ which correlates weakly with the HDRS [118] and has several advantages and disadvantages [119], but is widely used.

Sixth, one study [104] measured the efficacy only after six weeks, without follow-up measurement. This is a very short period for measuring the efficacy of IPT. Therefore, the results of this study may be questionable. Furthermore, these authors did not include an intention-to-treat analysis, which increases the risk of bias.

Finally, although a profound search has been performed, there is no complete certainty that all studies eligible for this review have been found. Furthermore, the search was directed only at published studies, automatically excluding unpublished data, causing possible publication bias.

\section{Conclusions}

It can be concluded that the differences between the effects and efficacy of several types of treatment are very small and they are often not significant. This in turn is consistent with a study concluding that the effects of psychotherapy for adult depression in meta-analyses are overestimated [27]. Nevertheless, usual care, as described in the study of Schulberg et al. [106], appears to be ineffective and is not recommended as a treatment for MDD. Therefore, psychotherapeutic treatments such as IPT and CBT, and/or pharmacotherapy are recommended as firstline treatments for depressed adult outpatients. This conclusion is consistent with a previous study [21], and review [26], and previous meta-analyses [28,29,32,33,55], although, as has been stated in the introduction, these studies had several limitations as well. Furthermore, it is recommended that the type of treatment is adjusted to the individual preferences of the patient.

Future research should focus on a larger sample including patients with MDD, while correcting for severity of depression. Since many studies focused on IPT combined with medication, it is recommended that these studies be included in future research as well. Furthermore, it is recommended that future studies included in a review, have longer follow-up periods. All studies should aim for the highest quality standards currently set.

\section{Additional files}

\author{
Additional file 1: Search strategy. \\ Additional file 2: Checklist. \\ Additional file 3: List of excluded studies.
}




\section{Competing interests}

The authors declare that they have no competing interests.

\section{Authors' contributions}

$\mathrm{MH}$ designed the study with the support of SE and TR. MH undertook the literature search with help from TE, identified potential and final selected articles, interpreted results, drafted and revised all versions of the manuscript, supported by SE and TR. In case of doubt during the screening and analyzing phase, TR was consulted. SE and TR supervised the development of the manuscript. All authors read and approved the final version.

\section{Acknowledgements}

This study was not funded by any grants. We thank Tim Ellermann and Henrietta Hazen for help during the development of an adequate search strategy. MH also thanks SE and TR for their support.

\section{Author details}

${ }^{1}$ Caphri, School of Public Health and Primary Care; Faculty of Health, Medicine, and Life Sciences, Maastricht University, Maastricht, the Netherlands. ${ }^{2}$ College of Pharmacy and Nutrition, University of Saskatchewan, Saskoon, Canada. ${ }^{3}$ Institute for Public Health and Nursing Research (IPP), University of Bremen, Bremen, Germany. ${ }^{4}$ Caphri, School of Public Health and Primary Care; Department of Health Services Research, Maastricht University, Maastricht, the Netherlands.

Received: 9 December 2011 Accepted: 7 January 2013 Published: 11 January 2013

\section{References}

1. American Psychiatric Association: Diagnostic and Statistical Manual of Mental Disorders, 4th edition, Text Revised. Washington DC: American Psychiatric Association; 2000.

2. Wittchen HU, Jacobi F: Size and burden of mental disorders in Europe - a critical review and appraisal of 27 studies. Eur Neuropsychopharmacol 2005, 15:357-376.

3. Kessler RC, Berglund P, Demler O, Jin R, Koretz D, Merikangas KR, Rush AJ, Walters EE, Wang PS: The epidemiology of major depressive disorder. Results from the national comorbidity survey replication (NCS-R). J Am Med Assoc 2003, 289:3095-3105.

4. Kessler RC, Berglund P, Demler O, Jin R, Merikangas KR, Walters EE: Lifetime prevalence and age-of-onset distributions of DSM-IV disorders in the national comorbidity survey replication. Arch Gen Psychiatry 2005, 62:593-602.

5. Depression. http://www.who.int/mental_health/management/depression/ definition/en/

6. World Health Organization: The World health report: 2001: Mental health: new understanding, new hope. 2001.

7. Kessler RC, Demler O, Frank RG, Olfsen M, Pincus HA, Walters EE, Wang P, Wells KB, Zaslavsky AM: US prevalence and treatment of mental disorders: 1990-2003. N Engl J Med 2005, 352(24):2515-2523.

8. Weihs K, Wert JM: A primary care focus on the treatment of patients with major depressive disorder. Am J Med Sci 2011, XXX:XXX.

9. Depressie (eerste revisie). Richtlijn voor de diagnostiek, behandeling en begeleiding van volwassen patiënten met een depressieve stoornis. http://www.psychiatrie-nederland.nl/Multidisciplinaire\%20Richtlijn\% 20Depressie\%20eerste\%20update\%202010.pdf.

10. Boelens W: Protocollaire behandeling van depressieve patiënten: cognitieve gedragstherapie. In Protocollaire behandelingen in de ambulante geestelijke gezondheidszorg, deel I. Edited by Keijsers GPJ, Minnen A, Hoogduin CAL. Houten: Bohn Stafleu Van Loghum; 2004:154-182.

11. Lewinsohn PM: The behavioral study and treatment of depression. In Progress in behavior modification, volume 1. Edited by Hersen M, Eisler RM, Miller PM. New York: Academic Press; 1975.

12. Beck AT, Rush AJ, Shaw BF, Emery G: Cognitive Therapy of Depression. New York: Guilford; 1979.

13. Blom MBJ, Jonker K: Protocollaire behandeling van depressieve patiënten: interpersoonlijke psychotherapie. In Protocollaire behandelingen in de ambulante geestelijke gezondheidszorg, deel II. Edited by Keijsers GPJ, Minnen A, Hoogduin CAL. Houten: Bohn Stafleu Van Loghum; 2004:96-116.

14. Klerman GL, Weismann MM, Rounsaville BJ, Chevron ES: Interpersonal Psychotherapy of Depression. New York: Basic Books; 1984.
15. Klerman GL, Weissman MM: New applications of interpersonal psychotherapy. Washington, DC: American Psychiatric Press; 1994.

16. Jonker K, Blom M: Interpersoonlijke psychotherapie. In Depressie: theorie, diagnostiek en behandeling. Edited by Albersnagel FA, Emmelkamp PMG, Van den Hoofdakker RH. Houten/Diegem: Bohn Stafleu Van Loghum; 1998:251-271.

17. Weissman MM, Markowitz JC, Klerman GL: Comprehensive guide to interpersonal psychotherapy. New York: Basic Books; 2000.

18. DiMascio A, Weissman MM, Prusoff BA, Neu C, Zwilling M, Klerman GL: Differential symptom reduction by drugs and psychotherapy in acute depression. Arch Gen Psychiatry 1979, 36:1450-1456.

19. Weissman MM, Prusoff BA, DiMascio A, Neu C, Goklaney M, Klerman GL: The efficacy of drugs and psychotherapy in the treatment of acute depressive episodes. Am J Psychiatry 1979, 136:555-558.

20. Reynolds CF, Frank E, Perel JM, Imber SD, Cornes C, Morycz RK, Mazumdar S Miller MD, Pollock BG, Hind Rufai A, et al: Combined pharmacotherapy and psychotherapy in the acute and continuation treatment of elderly patients with recurrent major depression: a prelimenary report. Am J Psychiatry 1992, 149:1687-1692.

21. Cascalenda N, Perry JC, Looper K: Remission in major depressive disorder: a comparison of pharmacotherapy, psychotherapy, and control conditions. Am J Psychiatry 2002, 159:1354-1360.

22. De Mello MF, De Jesus Mari J, Bacaltchuk J, Verdeli H, Neugebauer R: A systematic review of research findings of the efficacy of interpersonal therapy for depressive disorders. Eur Arch Psychiatry Clin Neurosci 2005, 255:75-82.

23. Hollon SD, Ponniah K: A review of empirically supported psychological therapies for mood disorders in adults. Depress Anxiety 2010, 27:891-932.

24. Parker G, Parker I, Brotchie H, Stuart S: Interpersonal psychotherapy for depression? The need to define its ecological niche. J Affect Disord 2006, 95:1-11

25. Pampallona S, Bollini P, Tibaldi G, Kupelnick B, Munizza C: Combined pharmacotherapy and psychological treatment for depression. A systematic review. Arch Gen Psychiatry 2004, 61:714-719.

26. Cuijpers P, Dekker J, Hollon SD, Andersson G: Adding psychotherapy to pharmacotherapy in the treatment of depressive disorders in adults: a meta-analysis. J Clin Psychiatry 2009, 70:1219-1229.

27. Cuijpers P, Van Straten A, Bohlmeijer E, Hollon SD, Andersson G: The effects of psychotherapy for adult depression are overestimated: a metaanalysis of study quality and effect size. Psychol Med 2010, 40:211-223.

28. Cuijpers P, Van Straten A, Hollon SD, Andersson G: The contribution of active medication to combined treatments of psychotherapy and pharmacotherapy for adult depression: a meta-analysis. Acta Psychiatr Scand 2010, 121:415-423.

29. Cuijpers P, Van Straten A, Van Oppen P, Andersson G: Are psychological and pharmacologic interventions equally effective in the treatment of adult depressive disorders? A meta-analysis of comparative studies. J Clin Psychiatry 2008, 69:1675-1685

30. Cuijpers P, Van Straten A, Van Schaik A, Andersson G: Psychological treatment of depression in primary care: a meta-analysis. $\mathrm{Br} J \mathrm{Gen}$ Pract 2009, 59:e51-e60

31. Gloaguen V, Cottraux J, Cucherat M, Blackburn IM: A meta-analysis of the effects of cognitive therapy in depressed patients. J Affect Disord 1998, 49:59-72.

32. Guidi J, Fava GA, Fava M, Papakostas Gl: Efficacy of the sequential integration of psychotherapy and pharmacotherapy in major depressive disorder: a preliminary meta-analysis. Psychol Med 2011, 41:321-331.

33. Cuijpers P, Geraedts AS, Van Oppen P, Andersson G, Markowitz JC, Van Straten A: Interpersonal psychotherapy for depression: a meta-analysis. Am J Psychiatry 2011, 168:581-592.

34. Thase ME, Greenhouse JB, Frank E, Reynolds CF III, Pilkonis PA, Hurley K, Grochocinski V, Kupfer DJ: Treatment of major depression with psychotherapy or psychotherapy-pharmacotherapy combinations. Arch Gen Psychiatry 1997, 54:1009-1015.

35. De Mello MF, Myczcowisk LM, Menezes PR: A randomized controlled trial comparing moclobemide and moclobemide plus interpersonal psychotherapy in the treatment of dysthymic disorder. J Psychother Pract Res 2001, 10:117-123.

36. Kroenke K, Shen J, Oxman TE, Williams JW Jr, Dietrich AJ: Impact of pain on the outcomes of depression treatment: results from the RESPECT trial. Pain 2008, 134:209-215. 
37. Poleshuck EL, Bair MJ, Kroenke K, Watts A, Tu X, Giles DE: Pain and depression in gynecology patients. Psychosomatics 2009, 50:270-276.

38. Poleshuck EL, Talbot NL, Su H, Tu X, Chaudron L, Gamble S, Giles DE: Pain as a predictor of depression treatment outcomes in women with childhood sexual abuse. Compr Psychiatry 2009, 50:215-220.

39. Karp JF, Scott J, Houck P, Reynolds CF III, Kupfer DJ, Frank E: Pain predicts longer time to remission during treatment of recurrent depression. $J$ Clin Psychiatry 2005, 66:591-597.

40. Yates WR, Mitchell J, Rush J, Trivedi MH, Wisniewski SR, Warden D, Hauger RB, Fava M, Gaynes BN, Husain MM, et al: Clinical features of depressed outpatients with and without co-occurring general medical conditions in STAR*D. Gen Hosp Psychiatry 2004, 26:421-429.

41. Ferrando SJ, Freyberg Z: Treatment of depression in HIV positive individuals: a critical review. Int Rev Psychiatry 2008, 20:61-71.

42. Andreescu C, Lenze EJ, Dew MA, Begley AE, Mulsant BH, Dombrovski AY, Pollock BG, Stack J, Miller MD, Reynolds CF: Effect of comorbid anxiety on treatment response and relapse risk in late-life depression: controlled study. Br J Psychiatry 2007, 190:344-349.

43. Brown C, Schulberg HC, Madonia MJ, Shear MK, Houck PR: Treatment outcomes for primary care patients with major depression and lifetime anxiety disorders. Am J Psychiatry 1996, 153:1293-1300.

44. Young JF, Mufson L, Davies M: Impact of comorbid anxiety in an effectiveness study of interpersonal psychotherapy for depressed adolescents. J Am Acad Child Adolesc Psychiatry 2006, 45:904-912.

45. Reynolds CF, Frank E, Kupfer DJ, Thase ME, Perel JM, Mazumdar S, Houck PR: Treatment outcome in recurrent major depression: a post hoc comparison of elderly ("young old") and midlife patients. Am J Psychiatry 1996, 153:1288-1292.

46. Mufson L, Moreau D, Weissman MM, Klerman GL: Interpersonal Therapy for Depressed Adolescents. New York: Guilford Press; 1993.

47. Levkovitz Y, Shahar G, Native G, Hirsfeld E, Treves I, Krieger I, Fennig S: Group interpersonal psychotherapy for patients with major depression disorder - pilot study. J Affect Disord 2000, 60:191-195.

48. Lutz W: Efficacy, Effectiveness, and Expected Treatment. Respnse in Psychotherapy. J Clin Psychol 2003, 59:745-750.

49. World Health Organization: International Statistical Classification of Diseases, 10th Revision (ICD-10). Geneva: World Health Organization; 1992.

50. Spitzer RL, Endicott J, Robins E: Research Diagnostic Criteria: rationale and reliability. Arch Gen Psychiatry 1978, 35:773-782.

51. Verhagen AP, De Vet HCW, De Bie RA, Kessels AGH, Boers M, Bouter LM, Knipschild PG: The Delphi-List: a criteria list for quality assessment of randomized controlled trials for conducting systematic reviews developed by Delphi consensus. J Clin Epidemiol 1998, 51:1235-1241.

52. Higgins JPT, Green S (Eds): Cochrane Handbook for Systematic Reviews of Interventions. Version 5.1.0 [updated March 2011]. The Cochrane Collaboration; 2011. Available from www.cochrane-handbook.org.

53. Weissman MM: Recent non-medication trials of interpersonal psychotherapy for depression. Int J Neuropsychopharmacol 2007, 10:117-122.

54. Jakobsen JC, Hansen JL, Simonsen E, Gluud C: The effect of adding psychodynamic therapy to antidepressants in patients with majo depressive disorder. A systematic review of randomized clinical trials with meta-analyses and trial sequential analyses. J Affect Disord 2011, in press.

55. De Maat SM, Dekker J, Schoevers RA, De Jonghe F: Relative efficacy of psychotherapy and combined therapy in the treatment of depression: a meta-analysis. Eur Psychiatry 2007, 22:1-8.

56. Hollon SD, Jarrett RB, Nierenberg AA, Thase ME, Trivedi M, Rush AJ: Psychotherapy and medication in the treatment of adult and geriatric depression: which monotherapy or combined treatment? J Clin Psychiatry 2005, 66:455-468.

57. Dorrepaal E, Van Nieuwenhuizen C, Schene A, De Haan R: De effectiviteit van cognitieve en interpersoonlijke therapie bij depressiebehandeling: een meta-analyse. Tijdschr Psychiatr 1998, 40:27-39.

58. Kotova E: A meta-analysis of Interpersonal Psychotherapy, Dissertation Abstracts International: Section B. Sciences and Engineering 2005, 66(5-B):2828.

59. Cuijpers $P$, Andersson G, Donker T, van Straten A: Psychological treatment of depression: results of a series of meta-analyses. Nord J Psychiatry 2011, 65(6):354-364
60. Cuijpers P, van Straten A, Schuurmans J, van Oppen P, Hollon SD, Andersson G: Psychotherapy for chronic major depression and dysthymia: A meta-analysis. Clin Psychol Rev 2010, 30(1):51-62.

61. Kriston L, Von Wolff A, Hölzel L: Effectiveness of psychotherapeutic, pharmacological, and combined treatments for chronic depression: a systematic review (METACHRON). BMC Psychiatry 2010, 10:95.

62. Blom MBJ, Spinhoven P, Hoffman T, Jonker K, Hoencamp E, Haffmans PMJ, Van Dyck R: Severity and duration of depression, not personality factors, predict short term outcome in the treatment of major depression. J Affect Disord 2007, 104:119-126.

63. Coulehan JL, Schulberg HC, Block MR, Madonia MJ, Rodriguez E: Treating depressed primary care patients improves their physical, mental, and social functioning. Arch Intern Med 1997, 157:1113-1120.

64. Watkins JT, Leber WR, Imber SD, Collins JF, Elkin I, Pilkonis PA, Sotsky SM, Shea MT, Glass DR: Temporal course of change of depression. J Consult Clin Psychol 1993, 61:858-864.

65. Ablon JS, Jones EE: Validity of controlled clinical trials of psychotherapy: findings from the NIMH treatment of depression collaborative research program. Am J Psychiatry 2002, 159:775-783.

66. Agosti V, Ocepek-Welikson K: The efficacy of imipramine and psychotherapy in early-onset chronic depression: a reanalysis of the National Institute of Mental Health Treatment of Depression Collaborative Research Program. J Affect Disord 1997, 43:181-186.

67. Barber JP, Muenz LR: The role of avoidance and obsessiveness in matching patients to cognitive and interpersonal psychotherapy: empirical findings from the Treatment for Depression Collaborative Research Program. J Consult Clin Psychol 1996, 64:951-958.

68. Blom MBJ, Hoek HW, Spinhoven P, Hoencamp E, Haffmans PMJ, Van Dyck R: Treatment of depression in patients from ethnic minority groups in the Netherlands. Transcult Psychiatry 2010, 47:473-490.

69. Brown C, Schulberg HC, Sacco D, Perel JM, Houck PR: Effectiveness of treatments for major depression in primary medical care practice: a post hoc analysis of outcomes for African American and white patients. J Affect Disord 1999, 53:185-192.

70. Carter JD, Luty SE, McKenzie JM, Mulder RT, Frampton CM, Joyce PR: Patient predictors of response to cognitive behaviour therapy and interpersonal psychotherapy in a randomised clinical trial for depression. $J$ Affect Disord 2011, 128:252-261.

71. Elkin I, Gibbons RD, Shea MT, Sotsky SM, Watkins JT, Pilkonis PA, Hedeker D: Initial severity and differential treatment outcome in the National Institute of Mental Health Treatment of Depression Collaborative Research Program. J Consult Clin Psychol 1995, 63:841-847.

72. Imber SD, Pilkonis PA, Sotsky SM, Elkin I, Watkins JT, Collins JF, Shea MT, Leber WR, Glass DR: Mode-specific effects among three treatments for depression. J Consult Clin Psychol 1990, 58:352-359.

73. Lave JR, Frank RG, Schulberg HC, Kamlet MS: Cost-effectiveness of treatments for major depression in primary care practice. Arch Gen Psychiatry 1998, 55:645-651.

74. Kim DM: Therapist effects and treatment effects in psychotherapy: Analysis on the National Institute of Mental Health Treatment of Depression Collaborative Research Program (NIMH TDCRP). Wisconsin: ProQuest Information \& Learning, Dissertation Abstracts International: Section B: The Sciences and Engineering; 2003.

75. Shea MT, Elkin I, Imber SD, Sotsky SM, Watkins JT, Collins JF, Pilkonis PA, Beckham E, Glass DR, Dolan RT, et al: Course of depressive symptoms over follow-up. Findings from the National Institute of Mental Health Treatment of Depression Collaborative Research Program. Arch Gen Psychiatry 1992, 49(10):782-787.

76. Segal ZV, Whitney DK, Lam RW, Group CDW: Clinical guidelines for the treatment of depressive disorders. III. Psychotherapy. Can J Psychiatry 2001, 46(Suppl 1):29S-37S.

77. Blom MBJ, Hoencamp E, Zwaan T: Interpersoonlijke psychotherapie voor depressie. Een pilot-onderzoek. Tijdschr Psychiatr 1996, 38:398-402.

78. Markowitz JC, Kocsis JH, Bleiberg KL, Christos PJ, Sacks M: A comparative trial of psychotherapy and pharmacotherapy for "pure" dysthymic patients. J Affect Disord 2005, 89:167-175.

79. Browne G, Steiner M, Roberts J, Gafni A, Byrne C, Dunn E, Bell B, Mills M, Chalklin L, Wallik D, et al: Sertraline and/or interpersonal psychotherapy for patients with dysthymic disorder in primary care: 6-month comparison with longitudinal 2-year follow-up of effectiveness and costs. J Affect Disord 2002, 68:317-330. 
80. Markowitz JC: Psychotherapy of dysthymia. Am J Psychiatry 1994, 151 (8):1114-1121.

81. Markowitz JC: Psychotherapy for dysthymic disorder. Psychiatr Clin North Am 1996, 19(1):133-149.

82. Svanborg C, Wistedt AA, Svanborg P: Long-term outcome of patients with dysthymia and panic disorder: a naturalistic 9-year follow-up study. Nord J Psychiatry 2008, 62(1):17-24.

83. Schulberg HC, Madonia MJ, Block MR, Coulehan JL, Scott CP, Rodriguez E, Black A: Major depression in primary care practice. Clinical characteristics and treatment implications. Psychosomatics 1995, 36:129-137.

84. Bulmash E, Harkness KL, Stewart JG, Bagby RM: Personality, stressful life events, and treatment response in major depression. J Consult Clin Psychol 2009, 77:1067-1077.

85. Kushner SC, Quilty LC, McBride C, Bagby RM: A comparison of depressed patients in randomized versus nonrandomized trials of antidepressant medication and psychotherapy. Depress Anxiety 2009, 26:666-673.

86. Frank E, Grochocinski VJ, Spanier CA, Buysse DJ, Cherry CR, Houck PR, Stapf DM, Kupfer DJ: Interpersonal psychotherapy and antidepressant medication: Evaluation of a sequential treatment strategy in women with recurrent major depression. J Clin Psychiatry 2000, 61(1):51-57.

87. Cuijpers P, Van Straten A, Warmerdam L, Andersson G: Psychological treatment of depression: a meta-analytic database of randomized studies. BMC Psychiatry 2008, 8:36.

88. Dunner DL: Acute and maintenance treatment of chronic depression. $J$ Clin Psychiatry 2001, 62:10-16.

89. Blanco C, Lipsitz J, Caligor E: Treatment of chronic depression with a 12week program of interpersonal psychotherapy. Am J Psychiatry 2001 158:371-375.

90. Miller IW, Keitner Gl: Combined medication and psychotherapy in the treatment of chronic mood disorders. Psychiatr Clin North Am 1996, 19(1):151-171.

91. Reinceke MA, Ewell Foster CJ, Rogers GM, Weill R: Medication or psychotherapy for severe depression. Am J Psychiatry 2000, 157(9):1528-1529.

92. Frank E, Kupfer DJ, Perel JM, Cornes C, Jarret DB, Mallinger AG, Thase ME, McEachran AB, Grochocinski VJ: Three-year outcomes for maintenance therapies in recurrent depression. Arch Gen Psychiatry 1990, 47:1093-1099.

93. Bressi C, Porcellana M, Marinaccio PM, Nocito EP, Magri L: Short-term psychodynamic psychotherapy versus treatment as usual for depressive and anxiety disorders: a randomized clinical trial of efficacy. J Nerv Ment Dis 2010, 198(9):647-652.

94. Croghan TW, Melfi CA, Dobrez DG, Kniesner TJ: Effect of mental health specialty care on antidepressant length of therapy. Med Care 1999, 37(4 Suppl Lilly):AS20-AS23.

95. Cuijpers P, Van Lier PA, Van Straten A, Donker M: Examining differential effects of psychological treatment of depressive disorder: an application of trajectory analyses. J Affect Disord 2005, 89(1-3):137-146.

96. Godfrin KA, Van Heeringen C: The effects of mindfulness-based cognitive therapy on recurrence of depressive episodes, mental health and quality of life: A randomized controlled study. Behav Res Ther 2010, 48(8):738-746.

97. Kingston T, Dooley B, Bates A, Lawlor E, Malone K: Mindfulness-based cognitive therapy for residual depressive symptoms. Psychol Psychother 2007, 80(Pt 2):193-203.

98. Schene AH, Koeter MW, Kikkert MJ, Swinkels JA, McCrone P: Adjuvant occupational therapy for work-related major depression works: randomized trial including economic evaluation. Psychol Med 2007, 37(3):351-362.

99. Schulberg HC, Block MR, Madonia MJ, Scott CP, Lave JR, Rodriguez E, Coulehan JL: The 'usual care' of major depression in primary care practice. Arch Fam Med 1997, 6(4):334-339.

100. Van Roijen LH, Van Straten A, Al M, Rutten F, Donker M: Cost-utility of brief psychological treatment for depression and anxiety. Br J Psychiatry 2006, 188:323-329.

101. Blom MBJ, Jonker K, Dusseldorp E, Spinhoven P, Hoencamp E, Haffmans J, Van Dyck R: Combination treatment for acute depression is superior only when psychotherapy is added to medication. Psychother Psychosom 2007, 76:289-297.

102. Luty SE, Carter JD, McKenzie JM, Rae AM, Frampton CMA, Mulder RT, Joyce PR: Randomised controlled trial of interpersonal psychotherapy and cognitive-behavioural therapy for depression. Br J Psychiatry 2009, 190:496-502.
103. Marshall MB, Zuroff DC, McBride C, Bagby RM: Self-criticism predicts differential response to treatment for major depression. J Clin Psychol 2008, 64:231-244.

104. Martin SD, Martin E, Rai S, Richardson MA, Royall R: Brain blood flow changes in depressed patients treated with interpersonal psychotherapy or venlafaxine hydrochloride. Arch Gen Psychiatry 2001, 58:641-648.

105. Schramm E, Zobel I, Dykierek P, Kech S, Brakemeier E, Külz A, Berger M: Cognitive behavioral analysis system of psychotherapy versus interpersonal psychotherapy for early-onset chronic depression: a randomized pilot study. J Affect Disord 2011, 129:109-116.

106. Schulberg HC, Block MR, Madonia MJ, Scott CP, Rodriguez E, Imber SD, Perel JM, Lave JR, Houck PR, Coulehan JL: Treating major depression in primary care practice. Eight-month clinical outcomes. Archives of General Psychiatry 1996, 53:913-919.

107. Elkin I, Shea MT, Watkins JT, Imber SD, Sotsky SM, Collins JF, Glass DR, Pilkonis PA, Leber WR, Docherty JP, et al: National Institute of Mental Health Treatment of Depression Collaborative Research Program. General effectiveness of treatments. Arch Gen Psychiatry 1989, 46:971-982.

108. O'Hara MW, Stuart S, Gorman LL, Wenzel A: Efficacy of interpersonal psychotherapy for postpartum depression. Arch Gen Psychiatry 2000, 57:1039-1045.

109. American Psychiatric Association: Diagnostic and Statistical Manual of Mental Disorders, Third Edition, Revised. Washington DC: American Psychiatric Association; 1987

110. American Psychiatric Association: Diagnostic and Statistical Manual of Mental Disorders (4th edition). Washington DC: American Psychiatric Association; 1994.

111. McCullough JP: Treatment for Chronic Depression. Cognitive Behavioral Analysis System of Psychotherapy. New York: Guilford Press; 2000.

112. Beck AT, Steer RA, Brown GK: Beck Depression Inventory: Manual. San Antonio: Harcourt Brace; 1987.

113. Padesky CA, Greenberger D: Clinician's guide to mind over mood. New York: Guilford Press; 1995.

114. Stewart DE: Hepatic adverse reactions associated with nefazodone. Can J Psychiatry 2002, 47:375-377.

115. Zimmerman M, Posternak MA, Chelminski I: Is it time to replace the Hamilton Depression Rating Scale as the primary outcome measure in treatment studies of depression? J Clin Psychopharmacol 2005, 25:105-110.

116. Bagby RM, Ryder AG, Schuller DR, Marshall MB: The Hamilton Depression Rating Scale: has the gold standard become a lead weight? Am J Psychiatry 2004, 161:2163-2177.

117. Santen G, Danhof M, Pasqua OD: Sensitivity of the Montgomery Asberg Depression Rating Scale to response and its consequences for the assessment of efficacy. J Psychiatr Res 2009, 43:1049-1056.

118. Schotte CKW, Maes M, Cluydts R, De Doncker D, Cosyns P: Construct validity of the Beck Depression Inventory in a depressive population. J Affect Disord 1997, 46:115-125.

119. Richter $\mathrm{P}$, Werner J, Heerlein A, Kraus A, Sauer H: On the validity of the Beck Depression Inventory. Psychopathology 1998, 31:160-168.

\section{doi:10.1186/1471-244X-13-22}

Cite this article as: van Hees et al:: The effectiveness of individual interpersonal psychotherapy as a treatment for major depressive disorder in adult outpatients: a systematic review. BMC Psychiatry 2013 13:22.

\section{Submit your next manuscript to BioMed Central and take full advantage of:}

- Convenient online submission

- Thorough peer review

- No space constraints or color figure charges

- Immediate publication on acceptance

- Inclusion in PubMed, CAS, Scopus and Google Scholar

- Research which is freely available for redistribution 